\title{
Education and Gender Disparity in West African Countries: The Nigeria Scenario
}

\author{
Biliamin Adekunle Adeyeye, M.Ed
}

Tai Solarin University of Education, Nigeria

\author{
Bright Ighorojeh,
}

Micheal Otedola College of Primary Education, Nigeria

Doi:10.19044/esj.2019.v15n28p43～URL:http://dx.doi.org/10.19044/esj.2019.v15n28p43

\begin{abstract}
Achieving gender parity in education and eradicating disparity in gender gap among developing nations especially the Sub-Saharan African countries, particularly Nigeria, has been a major area of interest and concern of global development discourses. Different reports, narratives, and arguments have been advanced to demonstrate that considerable progress has been made in closing the gaps of gender disparities in achieving educational parity. However, some levels of disparities still remain, mostly at girls' expense. This paper explores the review of various related materials and global initiative reports to assess education and gender disparities in West Africa more importantly from the Nigeria context. It elicits the notions of gender gaps and the extent of the achievement that has been made in the light of the Millenium development goals at a global glance. It identifies the barriers hindering the process of achieving parity status in education within the West African countries and suggest ways out of the predicament. The paper concludes that the quest for gender parity in Nigeria's educational system has witnessed some major progress while inequalities still persist. It then provides useful recommendations for better results.
\end{abstract}

Keywords: Education, Education Parity, Gender Disparity, Developing Countries, West Africa

\section{Introduction}

Over the last few decades, the issue of gender disparity and education equality has been a major topic in development discourses concerning Africa (Agyepong, 2001; Bolaji, Jalloh, Imonite and Walan-Jalloh, 2018; Okon, 2016; UNICEF, 2017). It has attracted lots of government attention among the African states and has remained a topmost priority for the United Nations agendas. A number of strategies and series of policies and legislative 
frameworks have been deployed globally to reduce to its optimal or possibly eradicate gender disparity and promote equality among gender divide at all levels of life aspirations, most importantly education. This includes policies and legislation on equal educational and employment opportunities, the 1995 Beijing Platform for Action, the GEF gender equality action plans, the WHO gender policy, FAO policy on gender equality, the Commonwealth gender equality policy, the Millenium Development Goal (MDG 2\&3), the Strategy Gender Initiative (SGI), the European Bank for Reconstruction and Development (EBRD) strategy, Convention against Discrimination in Education, Convention against all Forms of Discriminations against Women (CEDAW), Sustainable Development Goal 4, among many others. The objective of this paper is therefore set to review and analyze various research articles and reports as it concern with education and gender disparity gap within the context of the millennium development goals and related initiatives, eliciting the successes and shortfalls therein to determine the extent of achievement that has been made in addressing educational disparities in gender and identify the seemingly continuous gap. Using inferences from the reviewed literature findings to provide answers to the overarching education and gender disparity related questions. Questions such as to what extent has gender parity been achieved in Nigeria? What are the causes and areas of disparities? To what degree is the women folk affected by this disparity compared to men? What are the factors responsible for this disparity? What are the likely possibilities to curb this disparity in the even distribution of educational priorities specifically in Nigeria and West Africa as a whole?

\section{Background}

The construct of gender disparity has been narrowly conceived to suggest female disempowerment and disadvantaged against their male counterparts (Fawver, 2014; Pujar, 2016). This has forced the focus of research to look more into what becomes of women than men thereby, making the narrative of gender to appear like a women solely-based issue, whereas, gender concepts are seen to be more advanced beyond women and their problems to the problem of inequality between men and women (Okon, 2016; Pujar, 2016) 'issues disadvantaging more men than women have been understudied' (Stoet \& Geary, 2019). It may be important to note, however, that even though gender equity works against men as much as the women, in the main, much injustice have been meted out to women in many areas of life (Badey, 2013) particularly in West Africa.

According to Okon (2016), there is a growing concern that the population of women constitutes over an average of the entire world's population as noted by UNICEF 1998 and an estimated 50\% of the population of Nigeria is made up of women and girls as reported by UNSN 2001. Gender 
is less a women issue as it is a man's issue. It is essentially an issue of fundamental human rights and as well an issue of development concern (NEEDS-2, 2007, as captured in Okon, 2016). "This explain the need and reason behind the gender mainstreaming as a concept which came into widespread use with the adoption of the platform for action at the 1995 UN Fourth World Conference on Women held in Beijing, where it was unanimously affirmed that the advancement of women and the achievement of equality with men are matters of fundamental human rights and therefore, a prerequisite for social justice“" (Okon, 2016, p.312).

Efforts towards the realization of gender equality have since become a global call that has been identified as an essential condition for achieving national and sustainable development goals. Ejumudo (2013) highlights the attainment of gender equality as fundamental to the achievement of sustainable development, identifying it as a catalyst and a sine-qua-non. However, Iloegbunam (2006) as captured in Omoregie and Ihensekhien (2009) opined that history has not been kind to women and they have remained unnoticed and even belittled, despite the role they play both at home and in society. This inherent stereotypical gender perspective has grossly affected women educational advancement, mostly in West African states. Women education continue to receive lesser attention due to the long-aged traditional perception of women's roles in West African context and the continued economic hardship that has forced the common man to always make a choice between an opportunity cost and a foregone alternative. Women have been at the receiving end and the preferred choice for the alternative forgone. Omoregie and Ihensekhien (2009) explained that history has revealed perpetual discrimination against women in education in African society. This historical gender dominance and apathy arising from making a preferred choice among gender divide contributed to the entrenchment of inequality and disparities that have grossly affected women education in Nigeria. As a result, the males have had a history of dominance in Nigerian schools from the primary to tertiary levels (Omoregie \& Ihensekhien, 2009). This has left the searchlight of gender narrative on inequality in Africa to continue to beam more towards the female folks than their male counterpart.

\section{The Education Systems in Nigeria}

Education is a process through which an individual formally receives a systematic set of instructions. It connotes the act or process of imparting or acquiring general knowledge, developing the powers of reasoning and judgment, and generally of preparing oneself or others intellectually for mature life. It is synonymous to instruction, schooling, learning, training, literacy, civilization, study, information, discipline, culture and many more. It encompasses the acquisition of knowledge, skills, value, beliefs, and habits. 
Education is simply life and life is education. The essential value of education and its potentials in nation-building has informed the Nigerian government through its education system to engaged a series of educational policies and gender initiatives to show commitment towards development goals - such as Universal Basic Education (UBE), National Policy on Women (NPW), Education for all Fast Track Initiatives (EFA-FTI), National Economic Empowerment and Development Strategy (NEEDS), Universal Basic Education Act, National Policy on Gender in Basic Education among many others (see table 1). All these are aimed at providing greater access and ensuring the quality of basic education, and the systematic efforts in mainstreaming gender into all components of education policy at all level in Nigeria. Many similar policy initiatives, efforts, and measures have as well been committed by many Africa countries towards the achievement of the Millennium Development Goals such as the African Charter on Human and People's Rights (ACHPR); the Women Right Protocol of 2003; the ECOWAS Protocol on Democracy and Good Governance and the New Partnership for African Development (NEPAD) (Ejumudo, 2013).

The Nigeria education system is a multi-level system of education structured into different levels of educational requirements. These consist of the Early Child Care and Development; the Basic Education which encompasses Pre-Primary Education, Primary Education, the Junior Secondary Education; the Post-Basic Education in Senior Secondary Schools and Technical Colleges; and finally the Tertiary Education provided in Colleges of Education, Monotechnics, Polytechnics, and the Universities. The system draws the power of its operation from the National Policy on Education (NPE) a document adopted by the federal government of Nigeria as an instrument of national development. Nigeria's national education policy was first published in 1977 and has been successively followed by revised $2^{\text {nd }}, 3^{\text {rd }}$, $4^{\text {th }}, 5^{\text {th }}$ and $6^{\text {th }}$ editions published in $1981,1988,2004,2007$ and 2013 respectively. The revisions and updates of these editions have been necessitated by the need to address noticeable gaps found in the policy contents during the course of implementation, maintain currency and contemporary relevance, and to give adequate attention to new opportunities, developments, and possible future challenges. The policy document addresses the issues of imbalance in the provision of education in different parts of the country with regard to access, quality of resources and girls' education.

Table 1: The different policy initiatives with respect to their year of formation in

Nigeria

\begin{tabular}{|l|l|l|}
\hline S/N & Policy Initiatives & Year \\
\hline 1 & Blueprint on Women's Education & 1986 \\
\hline 2 & Nomadic Education Programme & 1986 \\
\hline 3 & National Commission for Mass Literacy and Non-formal Education & 1991 \\
\hline 4 & Family Support basic Education Programme & 1994 \\
\hline
\end{tabular}




\begin{tabular}{|l|l|l|}
\hline 5 & Universal Basic Education & 1999 \\
\hline 6 & National Policy on Women & 2001 \\
\hline 7 & Education for all-fast Track Imitative & 2002 \\
\hline 8 & Strategy for acceleration of Girls' Education in Nigeria & 2003 \\
\hline 9 & $\begin{array}{l}\text { National Economic Empowerment and Development Strategy } \\
\text { (NEEDS) }\end{array}$ & 2004 \\
\hline 10 & Universal Basic Education Act & 2012 \\
\hline
\end{tabular}

Source: Gender in Nigeria Report, 2012.

\section{Conceptualizing Gender, Gender Parity, and Gender Equality in Education}

For the purpose of this study, the concept of gender is focused on what gender is and what gender is not and how gender is variously perceived. Gender is not sex but the sex-role identity used by humans to emphasize the distinctions between males and females. There is a fundamental difference between gender and sex. Sex refers to the biological difference between women and men. It is biologically determined by birth and it is generally unchanging and universal while gender refers to the socially constructed roles, responsibilities, and identities assigned for women and men. It is the term used to describe the qualities and behaviours expected from men and women by their society (Akindele, 2002; Badey, 2013). "The fact that gender and gender differences are socially constructed is itself a primary issue to deal with" (Ekpe, Eja, \& John, 2014, p.16).

Gender is regarded as learned roles which are construed as not fixed but determined by social and cultural values which vary across countries and societal perspectives and is subject to possible changes through conscious government policies, societal awareness, media engagements and shift in traditions. (Akindele, 2002; Agyepong, 2001; Omoregie \& Ihensekhien, 2009). According to Omoregie and Ihensekhien (2009), Gender refers to the division of humanity along sex lines by the society which guides them on how to think about themselves, interact with others and determine their roles. They refer to gender as a dimension of social inequality which has historically favoured males against females.

\section{Gender Parity in Education}

Gender Parity concerns relative equality in terms of numbers and proportions of women and men, girls and boys, and is often calculated as the ratio of female-to-male values for a given indicator. Measures of gender parity index (GPI) in education help to compare and contrast participation and opportunities for schooling availed for both females and males. A GPI of 1 indicates parity between the sexes (UNICEF, 2018). If the index value measured is less than 1 it indicates that the value is higher for male than female, if it is greater than 1 it means the value is higher for female than male 
but if it is equal to 1 then it connotes parity among the gender divide (Education Policy and Data Center [EPDC], 2012).

Manlosa and Matias (2018), explain gender parity as a statistical means through which the numerical value and ratio of participation between the female to male are measured within a given indicator such as education. Given the scenario of primary education completion with an equal number of girls and boys in a specific country, the gender parity ratio for that indicator is one. The greater the difference between girls and boys, the lower is the gender parity value. 'Gender parity is a useful tool for assessing gender inequality in specific areas, in setting goals, and in assessing change and progress under specific indicators of gender equality'. By the foregoing it is important however to note that the distinction between the two concepts is that; gender equality is a means while gender parity is an end, these concepts must not be taken as same to avoid misinterpretation of means for an end. Gender parity is seen to have been achieved in most countries at the primary level of education even though the girls still remain at the mercy of disparities (UNICEF, 2018).

\section{Gender Equality in Education}

Unicef (2018) define gender equality to means that women and men and girls and boys enjoy the same rights, resources, opportunities, and protections. Rena (2005), opined that "the realization of equality between female and male students in education is dependent on the establishment of a social, political, economic and cultural framework that allows both genders to choose various educational courses regardless of their gender and without being bound by rigid cultural, religious beliefs or stereotyped gender roles"(p.3). This corroborates in some ways with Manlosa and Matias (2018) that gender equity can only be reflected in the difference made in women's lives, particularly in the labour context. It involves a substantive shift not in the proportion of men and women under a specific indicator but in the deeper dimensions of societal norms and scene of identities to be valued and respected equally, regardless of gender. They suggest that if equality is to be realized on gender then efforts should be advanced beyond statistical analysis to determine gender parity.

Manlosa and Matias (2018) agreed that much progress can still be made in actualizing equality in educational access and other social rights for women through supportive government policies that are gender-sensitive.

\section{Education and Gender Parity in the Light of MDGs at Global Glance and the Nigerian Scenario}

The year 2015 was chosen as a benchmark for the assessment of the millennium development goals (MDGs) (Ajiye, 2014; Durokifa \& AbdulWasi, 2016; UNESCO, 2016; UNICEF, 2018). MDGs goals is a widely 
accepted framework for measuring national and global development progress which has grabbed the attention of all the 191 member states of the United Nations Organization to pledge for its achievement by the year 2015 (WHO, 2010 as cited in Ajiye, 2014). UNICEF (2018) noted that the target of the millennium development goals in achieving universal primary education (UPE) benchmarked for 2015 was missed world over. According to the reports, there is still a long way to go before achieving UPE in some regions. The challenge is most acute in Sub-Saharan Africa, where net enrolment rate stood at 79 per cent in 2015, although the number of out-of-school children of primary school age declined globally from 100 million to 61 million between 2000 and 2015, progress has stalled since 2007. However, UNESCO highlights that most countries witnessed more of gender disparity in education at the secondary level than at the primary level. In 2015, 55 per cent of countries at the lower secondary level and 75 per cent of countries at the upper secondary level had not achieved gender parity in gross enrollment, compared to 34 per cent at primary level. (UNESCO, Global Education Monitoring Report 2016). According to the global gender gap report (2018): the distribution of the global gender gap across 149 countries covered by the 2018 report shows that:

The Global Gender Gap score stands at 68\%. This means that, on average, there is still a $32 \%$ gap to close. This highlight shows that the gap is still large across most of the 149 countries assessed. To date, no country has achieved parity, and only the top seven countries in the rankings have closed at least $80 \%$ of the gap. Among them, the top four are Nordic countries (Iceland, Norway, Sweden, and Finland), one is from Latin American (Nicaragua, 5th), one is from Sub-Saharan Africa (Rwanda, 6th) and two are from the East Asia and the Pacific region (New Zealand, 7th, and Philippines, 8th). The top ten is completed by Ireland (9th) and Namibia (10th). (p. 7).

\section{Nigerian Scenario}

\section{Nigeria MDG Achievement in Basic Education}

Owing to the focus of this study which is mainly to explore the state of education and gender disparity clause in relevant literature and reports, the Nigeria 2015 Millennium Development Goals End-Point Report was reviewed to assess the situation around achievements in education and gender parity within the MDGs scope, the report gave an overview of activities around the MDG 2, which is to ensure that children universally - including both boys and girls - will be able to complete a full course of primary education by 2015 and MDG 3, which is to promote gender equality and empower women; as expatiated below: 
The net enrolment in basic education (as domesticated in Nigeria to mean six years of primary schooling and three years of junior secondary education) has had a fluctuating history of an upward trend to the mid-point assessment year. This positive trend was however halted in later years as a result of the disruptions brought about by the Boko-Haram insurgency. The insurgency led to the destruction of many schools with the school children constituting a large size of the internally displaced population. Consequently, the net enrolment of $60 \%$ in 1995 declined to the end-point net enrolment of 54\% in 2013. There is, however, a good policy environment provided by the Federal Ministry of Education and its parastatal which will aid significant growth in net enrolment once the Boko-Haram phenomenon is effectively checked. With respect to primary six completion rate, the trend and end-point status show strong and significant progress. Nigeria remained largely on track towards achieving this indicator. The completion rate which stood at $73 \%$ in 1993 trended upwards in most of the subsequent years culminating in $82 \%$ at the end-point year. The policy environment is good and supportive of consolidation of the achievements. There are however variations across states which need to be addressed in efforts to consolidate the achievements. The literacy rate trended marginally upwards in most of the years from 64\% in 2000 to $66.7 \%$ in 2014 . The significant rate of $80.0 \%$ achieved in 2008 could not be sustained. There were marked variations across states and between the north and the south. With respect to variations across geopolitical zones, the North-east recorded the highest rate of illiteracy with the insurgency compounding the problem. However, the policy environment at both the national and sub-national levels is very supportive especially with active and growing collaboration between Nigeria and international development partners.

Overall Conclusion on Goal 2: Appreciable progress but goal not met. (MDGs Nigeria Report, 2010).

\section{Nigeria MDG Achievement in Gender Parity (Education and Women Empowerment)}

There are eight Millenium Development Goals with measurable targets aimed at improving lives of the world's poorest people, four out of these goals are directly related to gender to show the enormity of what gender portends to global development. This includes achieving universal primary education; promoting gender equality and the empowerment of women; reducing infant and child mortality, and improving maternal health. According to the Nigeria 2015 Millennium Development Goals End-Point Report: 
The pursuit of gender parity in basic education in Nigeria has witnessed strong progress when seen against the prevailing patriarchal culture and practices in most parts of the country. There has been a steady increase in the ratio of girls to boys in basic education in Nigeria with the end-point status of $94 \%$ in 2013 being a significant achievement compared to the $82 \%$ achieved in 1991. The statistics from both the World Bank and Multiple Indicator Cluster Survey (MICS) corroborate the high gender parity index recorded by Nigeria. The success at the basic education level has not been replicated at the tertiary level where there is weak progress even though the policy environment has been supportive at every level of the educational pipeline. Similarly, Nigeria has not done well in the area of the proportion of women in wage employment in the non-agricultural sector with an end-point status of 7.7\% in 2010 (the most recent data). However, in terms of women's contribution to the total labour force in both agricultural and non-agricultural sectors, the proportion has considerably increased to a record of $37.7 \%$ in 2014 . The ILO statistics corroborate this with a $48.1 \%$ increase in 2011. As regards the proportion of seats held by women in the National Parliament, Nigeria has done badly, with an end-point status of 5.11\% in 2015 against the expected target of 35\%. The prevailing patriarchal culture and practices remain a major factor against women's access to elective positions. This is however not the case with women in appointive positions as over $30.0 \%$ of women got appointed to higher-level political decision making positions in recent years.

Overall Conclusion on Goal 3: Strong progress made in gender parity but weak progress in women empowerment. Goal not met. (MDGs Nigeria Report, 2010).

\section{Identified Barriers Limiting the Attainment of Education Parity in Nigeria}

Gender inequality is indeed prevalent in many developing countries which make keeping girls in school and supporting their success for continuous secondary and higher education an overriding challenge (Agyepong, 2001). According to the UNESCO Institute of Statistics (USI) global education database of the 2016 reference year, there has been a constant and seemingly unabated figure over the past five years concerning out of school which shows that one out of every three children, adolescent and youth are out of school - with girls more likely to be excluded than boys. The report confirms that about 263 million or approximately 1 in 5 children ages 6-17 are out of school and for every 100 boys there are 123 girls already denied the right and access to education. Some varied social underlying factors such as 
poverty, geographical marginalization, insurgency, the dearth of quality education and inadequate infrastructures have been identified as possible major barriers that deter children most importantly females from attending school (UNICEF, 2018) this has kept the out of school number at a continuous alarming rate. This conforms with the 2017 UNICEF previous findings, that children enrolled in primary schools are less likely to complete schooling based on various factors. It stated that of the $60 \%$ male that started primary school, $79.9 \%$ of them complete it. Whereas, of the $54.8 \%$ of primary schoolaged female students enrolled in primary school $96.5 \%$ of them complete primary education eventually.

From the Nigerian context, Obasi (1997) identify long-held traditional beliefs in male superiority and female subordination as the bane of barriers to girls' education and the major link to the gender imbalance in participation in schooling. Nworgu and Nworgu (2013) suggest substantial rural-urban disparities as one of the crucial factor responsible for the educational gap. These factors vary greatly across regions and even within regions in Nigeria and the degree of its occurrent also differ. The variance is a product of different elements that range from regional diversities to communal cultures, religious affiliation beliefs, and security factors among others stated hitherto. The gap is more pronounced in northern Nigeria than the southern parts. According to (UNICEF, 2017) $60 \%$ of Nigeria's out of school children are from the North with a sharp drop in girl-child enrolment in the region due to the low perception of the value of education and early marriages and security crises. This phenomenon by extension is also partly informed by lags in diligent implementation of government policies and administrative consolidations. In the view of Azuh, Egharevba and Azuh (2014) majority of relevant policies have not been translated into anticipated actions to promote equality in gender and this has continued to widen the gap and make it appear seemingly unabated. The Council on Foreign Relations (2019) argued that legal barriers are among factors limiting the closure of the gender gap in Nigeria. It was believed that Nigeria's law has been holding women back from closing the economic gender gap, that women are not protected by any law mandating nondiscrimination in employment based on gender. According to Bolaji et al. (2018), the issue of bottle-neck in bureaucracy and internal wrangling within policy implementation structures form a major setback in the achievement of educational access for all among the African countries, particularly Nigeria. Given the foregoing, for Nigeria and other West African countries to overcome this menace and put the continent on the track of educational success devoid of gender disparities and discriminations, geared towards sustainable future, the position of Bolaji et al., that - the realization of education for all in 2050, depends heavily on the understanding of the African 
bureaucrats that collective will or responsibility is the only way to actualized policy initiatives - then becomes a path to follow.

\section{Conclusion}

This paper has offered a critical and analytical reportage on the issue of education and the narrative of gender disparity in West Africa countries with an emphasis on Nigeria. The article posits from evidence-based positions corroborated by Multiple Indicator Cluster Survey (MICS), Nigeria MDG's reports, and statistics from both the World Bank and the Global Gender Gap Index that, the quest for gender parity in Nigeria's educational system has witnessed some major of progress. The progress achieved has been a direct result of the supportive policy initiatives adopted by the Nigerian government. The policy initiative includes the Universal Basic Education Policy, National Policy on Gender Education, Education for All Policy and the Federal Teachers Scheme initiative to ensure the effective realization of the MDG's goal on education.

The work has also identified various barriers capable of limiting or stalling the consolidation of the measure of success recorded so far. Basically the traditional and long-age beliefs of the higher value of men and the superiority of male over female, the Boko-Haram insurgency in the Northern/Eastern region of the Nigerian state. And more fundamentally the dearth of translating policies into actions. The government at all levels is not unaware of these barriers and to their credit; they have undertaken considerable initiatives to surmount the insurgency and take necessary steps but more actions are required.

The government must come-up with requisite policies to tackle and discourage gender disparity. Such policy must be mainstreamed as a fundamental rights issue and application of appropriate sanctions if violated. Some northern states have tried in these regards. They have enacted laws to prohibit street trading, street begging, hawking and withdrawal of girls from schools. However, the effects of these policies have been minimal and the major reason being the problem of enforcement and application of necessary sanctions. For these policies to have meaningful effects there must be enforced terms and appropriate sanctions applied when violated.

In addition to the above recommendations, there is a need for a mass public orientation and public education through the National Orientation Agency on the falsity of the pervasive belief of male superiority and female subordination. The orientation should educate the girl to know that if educated, she can compete and stand shoulder to shoulder with her male counterpart in any regards. The poster faces of the orientation should be women who are educated and have excelled in their chosen career. The idea is for them to serve as inspiration and motivation to the young girls. 


\section{References:}

1. Agyepong, R. (2001). Gender and African education: A critical analysis of the literature. (Masters Thesis) Ontano Institute for Studies in Education of the University of Toronto.

2. Ajiye, S. (2014). Achievements of Millennium Development Goals in Nigeria: A critical examination.International Affairs and Global Strategy, 25, pp, 24-36.

3. Akindele, R.I. (2002). A pragmatic investigation of gender issues in workers motivation in Nigeria. The African Economic and Business Review, 3(1).

4. Azuh,D.,Egharevba,M.D.,\&Azuh,A.E. (2014). Gender discrimination and national politics: The Nigerian case. Covenant University Journal of Politics and International Affairs (CUJPIA), 2(2), 19-30.

5. Badey, P.B. (2013). Gender equity and sustainable development in Nigeria: The philosophical perspective. An International Journal of Language, Literature and Gender studies, 2(2), $97-103$.

6. Bolaji, S.D., Jalloh, S., Imonitie, B., \& Walon-Jalloh, A. (2018). Reversing the trend of educational disparity in West Africa. International Journal of Learning and Development, 8(2), 130-142. doi:10.5296/ijld.v8i2.13089

7. Council of Foreign Relations (2019). Nigeria's law hold women back and the economy suffers. [Accessed August 30, 2019] Available https://www.cfr.org/blog/nigerias-laws-hold-women-back-andeconomy-suffers

8. Durokifa, A.A.,\&Abdul-Wasi, B.M. (2016). Evaluating Nigeria's achievement of the millennium development goals (MDGs): Determinants, deliverables, and shortfalls. Africa's Public Service DeliveryandPerformanceReview.4,pp.656683.10.4102/apsdpr.v4i4.

9. Education Policy Data Centre (2012). Gender parity indices. [AccessedJune6,2019].Available https://www.epdc.org/topic/genderparity-indices

10. Ejumudo, K.B.O. (2013).Gender equality and women empowerment in Nigeria: The desirability and inevitability of a pragmatic approach. Developing Country Studies, 3(4). Retrieved from www.iiste.org

11. Ekpe, D.E., Eja, A.E., \& John, E.I. (2014). Women, gender equality in Nigeria: A critical analysis of socio-economic and political gender issues. Journal Research in Peace, Gender and Development (JRPGD),4(1),15-20.DOI: http:/dx.doi.org/10.14303/jrpgd.2014.009

12. Fawver, M.D. (2014). Gender Similarities and Differences in Experiences of Public School Administrator. Electronic Theses and Dissertations. Paper 2438. http://dc.etsu.edu/etd/2438 
13. Manlosa, A. \& Matias, D.M. (2018). From gender parity to gender equality: Changing women's lived realities. German Development Institute 5. Available from https://blogs.die-gdi.de/en/

14. Nigeria 2015 Millennium Development Goals End-Point Report. Abuja.

15. Nworgu, B.G., \& Nworgu, L.N. (2013). Urban-rural disparities in achievement at the basic education level: The plight of the rural child in a developing country. Developing Country Studies, 3(14).

16. Obasi, E. (1997). Structural adjustment and the gender access to education in Nigeria. Gender and Education, 19, 161-177.

17. Okon, D.E. (2016). Gender mainstreaming as index of sustainable human development in Nigeria:Problems and prospects. International Journal of Scientific Research in Education, 9(4), 311-324.

18. Omoregie, N.\& Ihensekhien,O.A.(2009). Persistent gender inequality in Nigerian education.

19. Pujar, S. (2016).Gender inequalities in the cultural sector. Culture Action Europe. Brussels-Belgium.

20. Rena, R. (2005). Gender disparity in education: An Eritrean perspective. The Global Child Journal, 2(1), 43-49.

21. Stoet, G., \& Geary, D. C. (2019). A simplified approach to measuring nationalgenderinequality. PloSone, 14(1).doi:10.1371/journal.pone.0 205349

22. The Global Gender Gap Report (2018). World Economic Forum, Cologny/GenevaSwitzerland.Available

https://www.weforum.org/reports/the-global-gender-gap-report-2018

23. UNESCO (2016). Global Education Monitoring Report. [Accessed June6,2019].Availablehttps://en.unesco.org/gemreport/taxonomy/ter $\mathrm{m} / 198$

24. UNESCO (2018). Education data release: One in every five children, adolescent and youth is out of school. [Accessed June 6, 2019]. Available http://uis.unesco.org/sites/default/files/documents/fs48onefive-children-adolescents-youth-out-school-2018-en.pdf

25. UNICEF (2017). Primary Education. [Accessed June 6, 2019] Available https://data.unicef.org/topic/education/primary-education/

26. UNICEF (2018). Gender and Education. [Accessed June 6, 2019] Available https://data.unicef.org/topic/gender/gender-disparities-in education/ 